\title{
Are Claims Of Transparency All They Are Cracked Up To Be?*
}

\author{
$\underline{\text { Philip J. Grossman }}^{\mathrm{a}}$, Mana Komai ${ }^{\mathrm{b}}$ and Evelyne Benie ${ }^{\mathrm{b}}$ \\ ${ }^{a}$ Department of Economics, Monash University, Clayton Victoria \\ Email: grossman.philipj@gmail.com \\ ${ }^{b}$ Department of Economics, Saint Cloud State University, St. Cloud, Minnesota, USA.
}

\begin{abstract}
The current "buzzword" among leaders is "transparency." Hardly a day goes by that a group leader (politician, manager, or administrator) doesn't state that he values transparency and will provide full disclosure of his information and actions. This project tests experimentally whether or not leaders, when given a choice, actually reveal a preference for transparency. Our experiment is based on a theoretical model by Komai, Stegeman, and Hermalin (2007). Fifteen subjects are randomly assigned to five groups of three. Each group separately participates in an investment game with three possible return scenarios (high, average, and low) that are equally likely to happen. Investing in the low-return scenario is not profitable to either individual group members or the whole group. In the average-return scenario, group well-being is maximized if all the group members invest in the project, but full cooperation may not be achieved simply because the dominant strategy of the individuals is to free ride on others. In the high-return scenario full cooperation is also optimal for the group, but subjects may or may not coordinate on full cooperation because they may fail to coordinate their efforts with the others. We consider a leader-follower setting. Only one member of the group (the leader) observes the scenario. The leader moves before the rest of the group members and first decides whether or not to invest in the project. The leader then chooses between two information regimes: revealing his decision and the return scenario to the rest of the group or revealing his decision but not the return scenario. Absent any information provided by their leader, followers know only the possible return scenarios and their likelihoods. They do not know which scenario is assigned to their group. Given the leaders' information choices and investment decisions, the relevant information will be conveyed to the followers. The followers then will separately and simultaneously decide whether or not to invest in the project (followers do not know anything about the different information regimes). This is realistic in many real-world circumstances because in many business or political environments the leaders have exclusive access to critical information and are in charge of deciding whether or not to reveal the details of their information and actions to their potential followers; in many circumstances it is practically difficult for the followers to verify the real information or the leaders' actions.
\end{abstract}

Keywords: Transparency, leading by example, free-riding, cooperation. 


\section{Are Claims Of Transparency All They Are Cracked Up To Be?}

\section{INTRODUCTION}

The current "buzzword" among leaders is "transparency." Hardly a day goes by that a group leader (politician, manager, or administrator) doesn't state that he values transparency and will provide full disclosure of his information and actions. Schwarz (2010) writes that "[T] he definition of 'transparency' is to share all relevant information in a way that is timely and valid. Being transparent means sharing the reasoning and intent underlying your statements, questions and actions (p. 56, emphasis added)."

Deloitte $(2008,2010)$ Ethic \& Workplace Surveys highlight the importance of transparency for followers. In the 2010 survey, $46 \%$ of respondents said a lack of leader transparency would cause them to seek new employment. Thirty-two percent ranked transparency most important in building trust in the workplace. In the 2008 survey, 72\% cited transparency's role in creating a more engaging and productive workplace. Bennis (2009) argues that a lack of transparency can be a serious problem, lowering morale; providing information boosts both morale and performance. Shaffer (1994) argues there is a shift from patriarchy to partnership and that empowerment and higher productivity require the sharing of information. Wilson (2009) contends that if leaders trust and look out for their employees, employees are more engaged and more willing to expend discretionary effort.

Vogelgesang and Lester (2009) argue that leader transparency includes “... sharing relevant information during interactions with followers (p.253)." Leaders who share relevant information are perceived as more "authentic" and followers are more likely to be loyal to authentic leaders. Sharing information creates common goals, providing followers something they can be loyal to. Transparency builds trust, follower engagement and ultimately enhances follower performance.

Norman et al. (2010) offers empirical evidence consistent with these arguments. Their work examines the linkage between transparency and trust in the leader. The authors conduct a field experiment with a $2 \times 2$ betweengroup design. There are four leadership scenario conditions concerning company downsizing. Three hundred four working adults were described a fictitious organization on the verge of downsizing. Subjects read one of four variations of a script involving the leader's positive psychological capacities (high or low) and transparency (high or low). Subjects then completed a survey rating leader trustworthiness and effectiveness. Leaders with high positive psychological capacities and high transparency were rated as significantly more trustworthy and effective.

What the literature fails to address is: How is a follower to know if his or her leader is actually being transparent or is just engaging in cheap talk? A leader's claim that the information provided followers is complete and true is not verifiable before the followers must act; the completeness and veracity can only be determined after the fact. This project tests experimentally whether or not leaders, when given a choice, actually reveal a preference for transparency (i.e. they reveal all relevant information to their followers). ${ }^{1}$

\section{THE EXPERIMENT}

We design our experiment based on a theoretical model by Komai et al. (2007). Fifteen subjects are randomly assigned to five groups of three. ${ }^{2}$ Each group separately participates in a one-shot, collective action, investment game with three possible return scenarios (high, average, and low) that are equally likely to happen (see Table 1). Investing in the low-return scenario (S3) is not profitable for either individual group members or the whole group. In the average-return scenario (S2), group well-being is maximized if all group members invest in the project, but full cooperation may not be achieved because the dominant strategy for each group member is to free ride on others. In the high-return scenario (S1), full cooperation is also optimal for the group, but members may not coordinate on full cooperation because they may fail to coordinate their efforts with the others.

We consider a leader-follower setting. Only one member of the group (the leader) observes the project scenario. The leader decides, before the rest of the group members, whether to invest in the project. The leader then chooses between two information regimes: transparent (i.e. revealing his decision and the return scenario) or not transparent (i.e. revealing his decision but not the return scenario).

\footnotetext{
${ }^{1}$ In this paper, leaders, if they reveal information, must be truthful.

${ }^{2}$ There were two sessions of only six subjects due to low turnout.
} 
Table 1: Scenarios 1, (2), and 3 Payoffs

\begin{tabular}{|c|c|c|}
\hline & Invest & Not Invest \\
\hline \multirow{3}{*}{ All } & 20 & \\
& $(13)$ & - \\
\hline \multirow{3}{*}{2} & $\mathbf{0}$ & 17 \\
& 13 & $(15)$ \\
& $(9)$ & $\mathbf{8}$ \\
\hline \multirow{3}{*}{1} & $\mathbf{0}$ & 14 \\
& 7 & $(12)$ \\
0 & $(5)$ & $\mathbf{9}$ \\
\hline & $\mathbf{0}$ & 10 \\
& & $\mathbf{1 0}$ \\
\hline
\end{tabular}

Given the leaders' investment decisions and information regime choices, the relevant information is conveyed to the followers. The followers then separately and simultaneously decide whether to invest in the project (followers do not know anything about the different information regimes).

A total of 222 subjects participate in fifteen sessions with either six or 15 subjects per session. ${ }^{3}$ Subjects are recruited to a common room (Room B). After signing consent forms, one-third of the subjects are selected at random to be leaders and move to a second room (Room A). ${ }^{4}$ Subjects are randomly and anonymously assigned to a three-person group (two from Room B and one from Room A). Subjects are given instructions which a proctor reads aloud. Room A instructions indicate that the leaders can reveal or not their groups' scenarios. Room B instructions indicate that the followers may or may not be informed of their groups' scenario, but they will be informed of their leaders' investment decision. Room B subjects do not know that the decision to not reveal the scenario was the Room A subject's choice.

The information regarding a group's scenario, the leader's investment decision, and the leader's decision to reveal the scenario is emailed to Room B. The appropriate information is relayed to the Room B followers. After the followers make their decisions, independently and simultaneously, earnings are calculated and the information is emailed to Room A. Subjects complete a short survey form to collect demographic information then paid in private and excused.

\section{RESULTS}

Our primary interest is in the behavior of our leaders, whether they choose the transparent information regime. If a leader holds transparency as a guiding principle, then his decision to be transparent should be independent of both his decision to invest and his group's scenarios. Recall that the definition of transparency is to "... share all relevant information in a way that is timely and valid (Schwarz, 2010). We therefore ignore the invest/not invest decision and define our null hypothesis as: A leader's transparency decision is independent of his group's scenario.

Table 2 reports the transparency decisions of our leaders by scenario. ${ }^{5}$ In both $\mathrm{S} 1$ and $\mathrm{S} 3$, the leader is better off removing any ambiguity. Coordinating on either all investing (S1) or all not investing (S3) is facilitated by revealing information about the scenario. Being transparent when transparency can only help you is easy. Not surprisingly, when transparency is beneficial (i.e. in S1 and S2), leaders opt for transparency; every leader but one, whether he invests or not, reveals to his followers his group's scenario.

In S2, being transparent makes the leader vulnerable; followers, knowing that they are in S2, can increase their earnings at their leaders' expense by free riding and not investing. Being transparent when transparency can hurt you is hard. Our results suggest that, in S2, when transparency exposes the leader to being exploited, leaders

\footnotetext{
${ }^{3}$ There were two sessions of six subjects and 14 sessions of 15 subjects.

${ }^{4}$ The Room A (B) subjects are not referred to as leaders (followers).

${ }^{5}$ The lower number in bold in each cell is the number not invest decisions.
} 
Grossman et al., Are Claims Of Transparency All They Are Cracked Up To Be?

Table 2: Leaders’ Transparency and Investment Decisions by Scenarios

\begin{tabular}{|c|c|c|}
\hline Scenario & Transparent & Not Transparent \\
\hline \multirow{2}{*}{1} & 20 & 0 \\
& $\mathbf{0}$ & $\mathbf{0}$ \\
\hline \multirow{2}{*}{2} & 17 & 24 \\
& $\mathbf{8}$ & $\mathbf{2 0}$ \\
\hline \multirow{2}{*}{3} & 12 & 1 \\
& $\mathbf{1 2}$ & $\mathbf{0}$ \\
\hline
\end{tabular}

are much less likely to opt for transparency. Less than half (17/41) of all S2 leaders, regardless of their investment decision, choose transparency. A $\chi^{2}$ contingency table test rejects our null hypothesis $\left(\chi^{2}(3)=32.9\right.$, p-value $\left.<0.001\right)$.

In Table 3 we report how followers respond to their leaders' decisions to invest or not and to be transparent or not. In S1 and S3, followers, with rare exceptions, follow they leaders' leads; if the leaders invest (do not invest),

Table 3: Behavior of Followers - Scenarios 1, (2), and 3

\begin{tabular}{|c|c|c|c|c|c|}
\hline \multirow{2}{*}{ Follower } & \multicolumn{2}{|c|}{ Transparent Leader } & & \multicolumn{2}{|c|}{ Not Transparent Leader } \\
\cline { 2 - 3 } Invest & Invest & Not Invest & & Invest & Not Invest \\
& 36 & 0 & 0 & 0 \\
& $(6)$ & $(3)$ & $(6)$ & $(5)$ \\
Not Invest & $\mathbf{0}$ & $\mathbf{2}$ & $\mathbf{1}$ & $\mathbf{0}$ \\
& $(12)$ & $(13)$ & & $(2)$ & 0 \\
& $\mathbf{0}$ & $\mathbf{2 2}$ & & $\mathbf{1}$ & $(35)$ \\
\hline
\end{tabular}

they invest (do not invest). In S2, when leaders do not invest, their decisions (to be transparent or not) do not appreciably influence their followers' decisions to invest or not. Less than $20 \%$ of the followers invest regardless of the leaders' transparency decision (binomial proportions p-value $=0.546$ ). When leaders invest, being transparent gives followers the information needed to determine if free riding is in their best interest. Our results suggest followers do exploit this information. Two-thirds of the followers free ride on their leaders when their leader is transparent. When the leader is not transparent, only $25 \%$ of the followers free ride. This difference is significant (binomial proportions p-value=0.049).

\section{CONCLUSION}

In many real-world business and political environments, leaders have exclusive access to critical information and are in charge of deciding whether or not to reveal the details of their information and actions to their potential followers. It is common for leaders in these circumstances to claim they value transparency and are in fact being transparent. However, it is practically difficult for the followers to verify the real information or the leaders' actions. This project tests experimentally whether or not leaders, when given a choice, actually reveal a preference for transparency.

Our empirical results indicate that, when it is to their advantage (our S1 and S3), leaders are transparent. When transparency places leaders in a vulnerable position (our S2), leaders are significantly less inclined to be transparent. Less than one-half of our leaders choose to be transparent in this scenario, and of those who did choose transparency, only one-half choose to invest, placing their selves in a position where they could be exploited by their followers.

One interpretation of our results is that leaders in S2 do not expect their followers to follow them (and our evidence suggests their expectations are accurate). Acting on this expectation, our S2 leaders either choose not to be transparent or, having chosen transparency, choose not to invest. 
Grossman et al., Are Claims Of Transparency All They Are Cracked Up To Be?

\section{ACKNOWLEDGEMENTS}

This work was funded by a SCSU Faculty Research grant.

\section{REFERENCES}

Bennis, W. (2009). Why transparency: A lack of candor kills trust. Leadership Excellence, 26, 3-4.

Deloitte LLP. (2008). Transparency matters. Deloitte 2008 Ethics \& Workplace Survey Results.

Deloitte LLP. (2010). Trust in the workplace. Deloitte 2008 Ethics \& Workplace Survey Results.

Komai, M., P.J. Grossman, and T. Deters. (2011). Leadership and information in a single-shot collective action game: An experimental study. Managerial and Decision Economic, 32, 119-134.

Komai, M., M. Stegeman, and B.E. Hermalin. (2007). Leadership and information. American Economic Review, 97, 944-947.

Norman, S.M., B.J. Avolio, and F. Luthans. (2010). The impact of positivity and transparency on trust in leaders and their perceived effectiveness. The Leadership Quarterly, 21,350-364.

Schwarz, R. (2010). Transparent leadership. Government Executive, 42, 56.

Shaffer, J. (1994). Leadership means telling the truth. Executive Excellence, 11, 12.

Vogelgesang, G.R. and P.B. Lester. (2009). How leaders can get results by laying it on the line. Organizational Dynamics, 38, 252-260.

Wilson, C. (2009). Trust: The critical factor in leadership. The Public Manager, 38, 48-52. 